Novak's Textbook of Gynecology

Edmund R. NovaK, A.B., M.D. and GeorgeanNa SeEgar Jones, M.D. Sixth edition. Pp. $842+x$, with 580 illustrations. London: Baillière, Tindall and Cox. 1961. I20s.

To students in this country this is probably the best known of all American textbooks of gynæcology. Written by the late Dr. Emil Novak-famed the world over for his textbook on gynæcological pathology and for his eminence in that field-it was first published more than 20 years ago. The fact that the present is the sixth edition of this book is sufficient evidence of its popularity.

With the untimely death of Dr. Emil Novak, authorship of the textbook has passed to his son, Dr. Edmund R. Novak, (co-author for the last edition), who in turn has been joined by Dr. Georgeanna Seegar Jones. These authors are to be congratulated on the new edition which, without losing any of its original character, has been thoroughly revised and brought up to date. Obsolete material has been eliminated and much that is new has been added, including new sections on cytology and abortion, while there is a totally new emphasis in those sections of the book dealing with endocrinology.

Except for operative details, every aspect of gynæcology is dealt with, each chapter has an extensive bibliography and the book is lavishly illustrated. The result is a textbook which can be recommended to the student seeking a full authoritative account of presentday American gynæcological practice.

\section{Advances in Biology of Skin \\ Vol III. Eccrine Sweat Glands and Eccrine Sweating}

Ed. William Montagna, Richard A. Ellis, Alene F. Silver. Pp. 266 + xiii. Oxford, London, New York and Paris: Pergamon Press. 1962. 63s.

This is Volume III of the series 'Advances in Biology of Skin'. Each volume represents a collection of papers, read by experts on various aspects of already specialised subjects, at Symposia held in Brown University, U.S.A.

The first two volumes in the series were entitled 'Cutaneous Innervation' and 'Blood Vessels and Circulation '; the present one deals in exhaustive detail with the eccrine sweat glands and eccrine sweating.

The papers have been edited for publication, prefaced by a descriptive list of contributions and rounded off by an index. The book maintains the thorough and workman-like approach of the first two volumes.

Each paper is made up of an account of some original experimental work by the writer together with an introduction to the particular aspect to be studied and a list of relevant references.

Such separate sections deal with, for example, gross anatomy and distribution of eccrine sweat glands, their histology and histo-chemistry, and the findings on electron microscopy. Further chapters consider aspects of behaviour-for instance in skin grafts or on exercise. Secretion and absorption is investigated; the patterns of sweating in terms both of the distribution of glands from one individual to another and of the response in time to stimuli of warmth are examined. The final chapter is devoted to the eccrine sweat defect in cystic fibrosis of the pancreas. In this chapter there is an account of the original work carried out by the authors (di Sant' Agnese and Gibson) on children with the disease, and it is perhaps more directly clinical in itso approach than the others; particularly valuable are $x$ survey of the genetic background and studies on the relatives of children with cystic fibrosis.

The book as a whole is beautifully printed and bound with admirable photographs and diagrams.

In spite of the formidably specialised sound of its title it is invaluable as a reference book and a source of stimulating thought-certainly for dermatologists, and $\mathbb{Q}$ possibly for many other clinicians and workers in the biological sciences too.

\section{The Hair and Scalp}

A Clinical Study. Agnes Savill and Clara Warren. Fifth edition. Pp. vii +326 , illustrated London: Edward Arnold. 1962. 42s.

Agnes Savill's 'The Hair and Scalp' was first. published in 1935. The latest edition has been revised, 6 the clinical chapters with the collaboration of Dr. Clara Warren. Dr. Arthur Rook contributes the chaptern on fungus diseases, the late Professor W. T. Astbury $\omega_{\text {W }}$ that on the molecular structure and elastic properties of the hair, and G. W. G. Jackman that on hair dyes.

There is a chapter on hirsutes in which the accounto of the histological development of treatment and the ${ }^{\supset}$ practical details and relative merits of diathermy and electrolysis are of interest and value to practising dermatologists.

For the rest of the book, it is difficult to know for whom it is intended. Apart from the chapters mentionedo above, much of it seems an uneasy blend of the person clinical, even anecdotal approach, with illustrative co histories, with an attempt to cover briefly the exper-o mental findings now available in profusion. A few references are appended, but these are neither re- $\frac{\partial}{\partial}$ presentative nor comprehensive.

On the purely clinical approach the authors' plan of chapter headings such as 'Diffuse Hair Fall', $\varrho$ 'Itching of the Scalp', 'Erythematous Eruptions ' results in a great deal of repetition. A more serious objection is that the statements made are often disputable - e.g. '. . . worry, fear, anxiety and stress are potent causes of extensive alopecia (areata) ...'; and that the treatments recommended are often out dated-e.g. autohæmo therapy, autogenous vaccines and thyroid 3 gland for alopecia areata.

The urge for completeness has led to the inclusion of very many conditions which might conceivably affect. the scalp. They cannot be dealt with adequately, and cheek-by-jowl with brief accounts of chicken pox and smallpox are comments on such rarities (where the 0 scalp is concerned) as xanthomata, sarcoidosis and ${ }^{3}$ sporotrichosis.

The printing, binding and reproduction of photographs is good. There are a few minor spelling errors; $N$ the index seems accurate.

The book reflects the twofold difficulty of writing on $N$ skin diseases in relation to any one site, and of discussing the hair and scalp, information on which in the present $\omega$ state of our knowledge all too easily oscillates between advanced biology and folk lore.

. 